\title{
Mentoring and Organizational Resilience. A Study of Manufacturing Companies in Rivers State.
}

\author{
*Accra Jaja, S and **Amah, E. \\ *Department of Management, Faculty of Management Science. Rivers State University of Science and \\ Technology. \\ **Department of Management, Faculty of Management Sciences. University of Port Harcourt
}

\begin{abstract}
The study examined the effect of Mentoring on Organizational Resilience in the Nigerian manufacturing industry. A total of 140 employees were randomly drawn from employees of the 31 manufacturing companies in Port Harcourt. The instruments used for data collection were questionnaire and oral interview. A total of 93 copies of the questionnaire were retrieved and analyzed. Spearman's Rank Correlation Statistical tool was used to test the hypotheses. The findings revealed that Mentoring is significantly related to Organizational Resilience. Based on these findings we concluded that Mentoring has significant influence on Organizational Resilience. The study therefore recommends that organizations should use its mentoring programmes as a knowledge retention measure that will strategically channel efforts towards organizational success. In other words mentoring should be used as a tool to enhance organizational resilience.

Key words: Mentoring, Organizational resilience, Organizational learning, Adaptive capacity, Dynamic capabilities.
\end{abstract}

\section{Introduction}

Organizations exist in a dynamic environment that is constantly changing. Managers have the task of coping with this changes as well as ensuring that their organizations survive and make profits. The concept of organizational resilience was borne out of the need for organizations to constantly keep themselves abreast of obstructions that may erode their entire existence and thereby take adequate precautionary measures which are regarded as anticipatory measures. The importance of organizations being resilient has a far reaching effect on the position of the entire enterprise. Organizational resilience is a continuously moving target which contributes to performance during business-as-usual and crisis situations (Mitroff, 2005). It requires organizations to adapt and to be highly reliable (Weick \& Sutcliffe, 2007), and enables them to manage disruptive challenges (Durodie, 2003).

Seville et al. (2008) defined organizational resilience as an organization's “...ability to survive, and potentially even thrive, in times of crisis". Being resilient can provide organizations with competitive advantage (Parsons, 2007). Organizations need to constantly respond not just to one time crisis or disaster event but to continuously anticipate and adjust to trends that permanently impair the earning power of the organization. The ability of any organization to maintain its standard and remain viable in the face of many perturbations today is a reflection of how resilient such organization could be. This is affirmed in Umoh (2009) who asserts that social organizations have to absorb environmental disturbances of all kinds in the process of achieving goals or objectives. He contends that the regulatory capacity of a subsystem is limited to its variety i.e. complexity. The regulator must generate higher variety than that of the situation being regulated, otherwise it is impossible to bring and keep the situation within the set of desirable states. This is also in consonance with the law of requisite variety cited in Umoh (2009) that "only variety absorbs variety". The concept of a system being viable can be seen in the context of how resilient it is. How proactive managers of organizations are in dealing with crisis, how prepared they are, is a measure of their viability.

Koontz, O'Donnel and Weihrich (1980) posits that an organized enterprise does not exist in a vacuum rather it is mutually dependent on its external environment, it is part of a larger system such as economic system, the industry to which it belongs and society. This implies that certain environmental factors such as natural disaster, economic factors, government regulations, socio-cultural factors, political instability, and employee turnover are disturbances that can affect the entire business operations of an organization. Umoh (2009) maintains that organizations must be at a homeostatic equilibrium or steady state being an open system it is and develop an error control measure as well in the form of feedback adjusters/adjuster organizers such as environmental inputs specialized facilities which checks and forestalls the organization enabling it to live on negative entropy.

Drucker (2008) asserts that as baby boomers leave the workplace, they are also taking the depth of their experience with them, thus, there is not only a decline in the number of workers, but there is also a shortage of experienced workers, and lack of documented practices. Hence, he contends that an organization 
has to provide today the men and women who can run it tomorrow. It has to renew its human capital by steadily upgrading its human resources. The next generation should stand in on the shoulders of their predecessors; establish a new "high business" baseline for the generation after them. For Drucker, an organization that just perpetuates today's level of vision, excellence, and accomplishment has lost the capacity to adapt.

Over the past decade, a great deal has been written about Mentoring and the role it plays in successful resilience of organizations (Bandura, 1977; Pitney and Ehler, 2004; Agulana and Awujo, 2005; Williams et al., 2002; Durodie, 2003; Dalziell \& McManus, 2004, Mitroff, 2005; Weick and Sutcliffe, 2007; Serville et al., 2008; Umoh, 2009; Amah, 2010; Alastir, 2010, Umoh and Amah, 2013). Despite these numbers of studies, little empirical studies exist on Mentoring and Organizational resilience in developing countries especially in Nigeria. To bridge this gap, this study examines the effect of Mentoring on Organizational resilience. By exploring the relationship between Mentoring and Organizational resilience, organizations can enhance their survival and effectiveness.

\section{Mentoring}

William, James and Susan (2002) defines mentor as a corporate manager who supervises, coaches, and guides selected Lower - level employees by introducing them to the right people and generally being their organizational sponsor. In reality, an informal type of mentoring goes on in most organizations on regular basis as older employees assist younger workers. Networking and having mentors is essential for succession planning because it builds and develops managers by widening their knowledge and better understanding of the overall operations and to prepare for task ahead. Agulanna and Awujo (2005) defines mentoring as the process of using specially selected and trained people to provide guidance and advice which will help to develop the careers to the people allocated to them. Mentoring is used to complement learning on the job which of course is the best way of obtaining particular knowledge and skills. According to Agulanna and Awujo mentors provide the following, to those assigned to them;

- Advice in drawing up self- development programmes

- General help with learning programmes

- Guidance on how to acquire the necessary and skill and knowledge to do a new job.

- Couching in specific skills

- Help in tacking projects by putting the trainers in the right direction that is helping them to help themselves.

Pitney and Ehler (2004) assert that mentoring is widely accepted as a strategy for facilitating the professional growth and development of students while they are socialized into a discipline. As a component of the professional socialization process, mentoring can influence how individuals prepare themselves and develop various values skills, knowledge and attitudes throughout their academic and professional careers.Delegation also is part of mentoring but this time around, it is one on one between the mentor and the mentee. The mentor assigns duties to the mentee who carries them out.

\section{Theory On Mentoring}

The ground theory was of the earliest theory explaining mentoring. According to Pitney and Ehler (2004), the base of ground theory is symbolic interactionism, which infers that an individual's behaviour is formed by social interactions; individuals are active in this process, and they make conscious decisions about how they will act in a given social setting (i.e clinical interactions between clinical instructor can create a condition for personal action and perception. Relating to this study, the social learning theory can be applied.

\section{Social Learning Theory}

Behaviourists emphasize the role of environment in directing behaviour. They work observing the ways in which their subjects respond to stimuli. The Behaviourist Albert Bandura's social learning theory of 1977 has become the most influential theory of learning and development. While rooted in the basic concepts of traditional learning theory, Bandura believed that direct reinforcement could not account for all types of learning. His theory added a social element, arguing that people can learn new information and behaviours by watching other people; known as observational learning (or modeling), this type of learning can be used to explain a wide variety of behaviours as in the case of employee learning of particular behaviours and new ways of doing things. Bandura posits that "learning would be exceedingly laborious, not to mention hazardous if people had to rely solely on the effects of their own actions to inform them what to do. Fortunately, most human behaviour is learning observationally through modeling; from observing others one forms an idea of how new behaviours are performed, and on later occasions this coded information serves as a guide for action. Basically there are three social learning concepts which are at the heart of social learning theory. First is the idea that people can learn through observation. Next is the idea that internal mental states are an essential part of this process. Finally, this theory recognizes that just because something has been learned, it does not mean that it will result on a change in behaviour. 
1. Observational Learning: People can learn through observation. In his famous Bobo doll experiment, Bandura demonstrated that children learn and imitate behaviour they have observed in other people. The children in Bandura's studies observed an adult acting violently towards a Bobo doll. When the children were allowed to play in the room, with the Bobo doll, they began to imitate the aggressive actions they had previously observed.

Relating this to our study, it then means that one can learn and imitate certain roles from another and live within these limits in whatever they do. Bandura identified three basic models of observational learning.

(a) A verbal instructional model which involves descriptions explanations of behaviour.

(b) A symbolic model, which involves real or fictional characters displaying behaviour in books, films, television programs or online media.

(c) Live model - In which an actual person is demonstrating the desired behavior.

2. Intrinsic Reinforcement: Mental states are important on learning. Bandura noted that external environmental reinforcement was not the only factor influence learning and behaviour. He described intrinsic reinforcement as formal of internal reward such as pride, satisfaction and a sense of accomplishment. The emphasis on internal thoughts and cognitions help connect learning theories. Bandura describes his approach as "social cognitive theory" while other textbooks places his theory as social learning theory.

3. Learning does not necessarily lead to a change in behaviour- while behaviourist believed that learning led to a permanent change in behaviour, observational learning demonstrates that people can learn new information without demonstrating new behaviour. This is because not all observed behaviour is effectively learned. This can be demonstrated in modeling process:

1. Attention: In order to learn, you need to pay attention. Anything that detracts your attention is going to have a negative effect on observational learning. If the model interesting or there is a novel aspect to the situation, you are far more likely to dedicate your full attention learning.

2. Retention: The ability to store information is also an important part of the learning process. Retention can be affected by a number of factors, but the ability to pull up information later and act on it is vital to observational learning.

3. Reproduction: Once you have paid attention to the model and retained the information. It is time to actually perform the behaviour you observed. Further practice of the learned behaviour leads to improvement and skill advancement.

4. Motivation: Finally, in order for observation learning to be successful, you have to be motivated to imitate the behaviour that has been modeled. Reinforcement and punishment play an important role in motivation.

Bandura's social learning theory has an important implication in the area of mentoring.

\section{Resilience}

Madni (2007) Defines resilience as the ability to anticipate a perturbation, to resist by adapting and to recover by restoring the pre-perturbation state as much as possible. McManus et al.; (2008) asserts that the numerous concepts that emerge from definitions of organizational resilience include knowledge of the environment, level of preparation, anticipation of perturbations, adaptation, capacity to recover, etc. The ability of organizations to absorb shock or develop resistance in the face of perturbances within its environment is a reflection of how prepared the organization can be.

Alastir (2010) contends that managers of resilient organizations should understand at board level, the environment in which their organizations operates, and be aware of changes which may represent a risk to their people, facilities, activities, services and supply chains. He maintains that managers need to understand the increasing complex cultural, political, legal, regulatory, economic, technological, natural and competitive context within which they operate and monitor key issues and trends that may impact on the objectives of the organization and the perceptions and values of external stakeholders.

Erica (2006) asserts that the economic implication of organizations being unprepared for crisis are significant. In September $11^{\text {th }}$ attacks, business interruption losses far exceeded the sum of all property losses. The importance of organizations being resilience can be well appreciated when we examine the decline in talented skills in certain workforces due to some unanticipated disaster or crisis or loss of key executives either as a result of death or being incapacitated to perform their duties.

In their argument, Amah and Daminabo-Weje (2004) are of the opinion that successful organizations were those who understood the dynamic nature of their environment (Competitors, technology, the availability and cost of finance, taxation, government policy and their customer needs and expectations). In this regard, they contend that a successful organization should evolve like a resilient eco-system constantly adopting to reflect the changing external environments. According to a United Nations Report (2005) event such as the 1998 ice storm in Quebec and Ontario and the August 2003 black out that affected 50 million people in the Midwestern and Eastern U.S.A and Ontario made governments realize that it had become crucial to develop a culture of resilience within organization. The restless and chaotic business operations make organizations vulnerable to a 
multiplicity of risks at all times. These environments require organizations to be flexible, adaptable and creative enough to respond to changing conditions which implies resilience for the organizations.

Smith (2002) describes organizational resilience in the context of being concerned with crisis prevention. According to Smith, there are two wide areas of crisis prevention. The first is concerned with the development of a crisis preparation culture; the second area is concerned with the ethical aspects of corporate behaviour and the creation of resilience as a consequence of suspect ethical behaviour.

Mallak et al (1997) identified four tools that will be used to help better prepare for crisis: (1) Risk analysis, (2) Contingency plan (3) Logic charts and (4) Tabletop exercises.

Stucliffe and Vogus (2003) believe that resilience "results from processes that promote competencies, restore efficacy, and encourage growth as well as structures and practices that enable these processes". According to Robb, a resilient organization "is able to create structure; dissolve it; provide safety in the midst of change; manage the emotional consequences of continuous transformation and change (anxiety and grief); and learn, develop, and grow".

The September 11 attacks and their aftermath are a living laboratory for those wishing to better understand how individuals, groups, and organizations respond under extreme disaster conditions. Along with other major disaster events, 9/11 revealed much about institutional responses and collective behavior in crises, underscoring what is already known about the social processes that characterize such events, while at the same time highlighting aspects of disasters that the literature has yet to explore fully (Tierney, 2003). Interesting data have emerged from reports written after 9/11. One such report looked at resiliency factors that could be implemented in private industry and the banking business based on what was learned from the attacks at the World Trade Center.

McManus's (2007) definition and indicators of organizational resilience, which she called, Relative Overall Resilience (ROR), is based on a definition of organizational resilience as, “.... a function of an organization's situation awareness, management of keystone vulnerabilities and adaptive capacity in a complex, dynamic and interconnected environment". This definition identifies three components or dimensions of organizational resilience; situation awareness, management of keystone vulnerabilities, and adaptive capacity. McManus (2007) also identified fifteen indicators of organizational resilience, five for each dimensions. Tierney (2003) talks about, robustness, redundancy, resourcefulness and rapidity, as well as four domains; technical, organizational, social and economic.

\section{Measures Of Organizational Resilience}

The measures of Organizational resilience include Organizational Learning, Adaptive capacity and Dynamic Capability.

\section{Organizational Learning}

Organizational learning has been defined in the web dictionary as an Organization-wide continuous process that enhances its collective ability to accept, make sense of and respond to internal and external change. Organizational learning requires systematic integration and collective interpretation of new knowledge that leads to collective action and involves risk taking as experimentation. Organizational Learning is an area of knowledge within organizational theory that studies models and theories about the way an organization learns and adapts. In organizational development (OD) is as characteristic of an adaptive organization, ie, an organization that is able to see changes in signals from its environment (both internal and external) and adapt accordingly. Learning is acquiring new, or modifying existing knowledge, behaviors, skill, values, or preferences and may involve synthesizing different types of information.

Aggestam (2006) posits that a learning Organization has a culture that supports learning and innovations both by individuals and by the organization. The environment promotes a culture of learning, a community of learners, and it ensures that individual learning enriches and enhances the organization as a whole. The process of learning must ultimately be made part of the culture, not just be a solution to a given problem. Learning organizations demand a new view of leadership, leader as designer. Culture begins with leadership, but because culture is the result of a group's accumulated learning the culture itself will later define the wanted leadership.

The first step in building a learning organization requires a leader who inspires the vision of the learning organization. To be a learning organization has no value in itself, it must always serve the broader aims of the organization. Shared visions emerge from personal visions. A Learning Organization has a design and a culture which takes in, and in a learning organization members know why. In other organizations they know how. Aggestam(2006) maintains that a learning organization is organized in such a way that it scans for information in its environment, creates information by itself, and encourages individuals to transfer know-ledge between the individuals in team. This must be guided by the structure and by the vision that is guided by the strategic leadership of the organization. 
Learning is when changes in knowledge happen inside an individual and learning and accumulation of (new) knowledge always starts with the individual. Individual learning does not necessarily imply changes in organizational knowledge. Organizational knowledge is knowledge independent of specific members in the organization, e.g. knowledge in know-ledge repositories, and knowledge embedded in policies, and routines. Organizational Learning (OL) is considered to depend on the collective cognitive processes of individuals. Individuals can be regarded as subsystems in the organization. The concept of learning organization regards the organization as an entity and focuses what are the characteristics such that encourages its members may learn. Organizational learning, on the other hand, focuses on how learning is developed in an organization.

\section{Adaptive Capacity}

In socio-ecological context, Walker et al., (2002) define adaptive capacity as an aspect of resilience that reflects learning, flexibility to experiment and adopt novel solutions, and the development of generalized responses to broad classes of challenges. Folke et al., (2003) identified four dimensions of adaptive capacity:

- $\quad$ Learning to live with uncertainty

- Nurturing diversity for reorganization and renewal

- Combining different types of knowledge for learning

- Creating opportunities for self-organization.

Armitage (2005) adapts Folke et al.,'s (2003) four dimensions for socio-institutions. In a socioinstitution context, adaptive capacity depends on the attributes of individuals, organizations and institutions that might foster learning when faced with change and uncertainty, such as willingness to learn from mistakes, engage in collaborative decision-making arrangements, and encourage institutional diversity. Adaptive capacity may be defined as the ability or inclination of individual or group to maintain an experimental attitude towards new situations as they occur and to act in terms of changing circumstances. Adaptive capacity is addressed in this context through two approaches; socio environmental, and organizational (McManus, 2007). An organization's ability to adapt is at the heart of their ability to display resilient characteristics. Amah and Baridam (2012) discuss the importance of adaptation and note that the aim is to create advantages over less adaptive competitors. This suggests that adaptive capacity is also linked to competitiveness.

Dalziell and McManus (2004) define adaptive capacity as, the engagement and involvement of organizational staff so that they are responsible, accountable and occupied with developing the organization's resilience through their work because they understand the links between the organization's resilience and its long term success. "...the ability of the system to respond to changes in its external environment, and to recover from damage to internal structures within the system that affect its ability to achieve its purpose". They also define adaptive capacity as relating to strong leadership and a culture which enables clear communication, good working relationships, and a shared vision across the organization. The organization is innovative and creative and people are able to constantly and continuously act to match or exceed the needs of the organization's operating environment in anticipation of, or in response to change. Dalziell and McManus (2004) go on to demonstrate the difference between adaptive capacity and vulnerability, which they argue are often used interchangeably because of the inclusion of adaptation in definitions of vulnerability. Vulnerability is defined by Dalzille and McManus (2004) as the amount of deviation from the organization's original state to the point at which it experiences significant change or impacts as a result of the disaster. Adaptive capacity then, is the envelope or space in which the organization's performance or management of the disaster fluctuates until it reaches an equilibrium.

Indicators AC1 to AC5 are McManus's (2007) indicators of adaptive capacity within her Relative Overall Resilience (ROR) model, and indicators AC6 and AC7 have been added as part of the updated model.

- AC1 - Minimization of Silo Mentality

- AC2 - Communications and Relationships

- AC3 - Strategic Vision and Outcome Expectancy

- AC4 - Information and Knowledge

- AC5 - Leadership, Management and Governance Structures

- AC6 - Innovation and Creativity

- AC7 - Devolved and Responsive Decision Making

\section{Dynamic Capabilities}

Teece, et al. (2010) defined Dynamic capabilities as "the firm's ability to integrate, build, and reconfigure internal and external competencies to address rapidly changing environments". Dynamic capabilities can be distinguished from operational capabilities which pattern to the current operations of an organization. Dynamic capabilities, by contrast, refer to "the capacity of an organization to purposely create, extend, or modify its resource base" (Helfat et al, 2007) cited in Teece, et al., (2010). The basic assumption of the dynamic capability is framework is that core competencies should be used to modify short-term competitive 
positions that can be used to build longer-term competitive advantage. These authors affirm that the Literature on dynamic capabilities grew out of (1) the resource based view of the firm and (2) the concept of "routines" in evolutionary theories of the organization (Nelson and Winter, 1982) cited in Teece, et al (2010).It thus provides a bridge between the economic-based strategy literature and evolutionary approaches to organization. They opine that three dynamic capabilities are necessary in other to meet new challenges. Organizations and their employees need the capability to learn quickly and to build strategic assets. New assets such as capability, technology and customer feedback have to be integrated within the company. Existing strategic assets have to be transformed or reconfigured. Treece's concept of dynamic capabilities essentially says that what matters for business is corporate agility; " the capacity (1) to sense and shape opportunities for threat, (2) to seize opportunities, (3) to maintain competitiveness through enhancing, combining, protecting, and when necessary, reconfiguring the business enterprise's intangible and tangible assets.

\section{Relationship between the Independent and Dependent variable Relationship between Mentoring and Organizational Learning.}

Mentoring is a developmental relationship that fosters individual abilities and knowledge and increases the understanding of immediate and long-term needs of the organization. Informal mentoring occurs without the organization's involvement. The aim is to ensure learning at all levels and to readily provide the HR needs. Gray, (1986) cited in Kelly and Lauderdale (1999) suggests that mentoring programmes can systematically meet career development needs-thus enabling the organization to address successfully, its own need for management succession. Wilson and Elman,(1990) cited in Kelly and Lauderdale (1999) observe that mentorship provide context for socialization that transfers organizational culture, and that individual benefits for protégés are apt to translate into organizational benefits such as the stronger performance and increased loyalty. Research demonstrates that productivity results improve from $22 \%$ for training alone to $88 \%$ when couching is added to training. Mentoring skills ensures that the mentee is very conversant with the job description.

\subsubsection{Relationship between Mentoring and Adaptive Capacity}

Mentoring exercise ensure that management does not lack the required skills whenever the need arises. By providing management with available talent even in the face of perturbations, the organization is sure to adapt within its environment. A consequence of a loss of resilience and adaptive capacity is loss of opportunity and response options (Walker and Holling in Mc Manus 2007). Olsson (2003) in a resilient social-ecological system, events such as disturbances can create opportunities for development and innovation. They contend that the social part of this capacity for ecosystem management can include the diversity of expertise and knowledge within organizations such as networks, which gather and store ecosystem knowledge and experience. Gunderson and Hourani (2003) argues that ecosystem resilience sustains the opportunity for social learning in a dynamic environment by providing a buffer that protects the system from the failure of management actions based upon insufficient understanding. It allows managers to learn and to actively adapt resource management policies thereby reducing the likelihood of moving into unsustainable and undesirable development trajectories.

Key individuals play essential roles in several aspects of the development of adaptive co-management systems, including facilitating information flow and coordinating knowledge for dealing with change and uncertainty, facilitating collaborative learning, building trust and resolving conflict. Key individuals provide leadership and visions for choosing sustainable and desirable social-ecological trajectories in the face of change. They are needed to access and develop social memory and initiate self-organizing processes (Olsson; 2003)

\section{Relationship between Mentoring and Dynamic Capabilities}

A mentor is seen as one who transfers knowledge and skill to a mentee. It is a personal experienced or more knowledgeable person helps to guide a less experienced or less knowledge person. It is an ongoing relationship of learning, dialog and challenge. Professional development is one of the functions in human resource management that can make the difference between success and failure, because it contributes to making a company more adaptable to changing and competitive environments (Palmer and Johnson, 2005; Becker, Hyland and Acutt, 2006). Among the techniques that organizations can use for professional development are mentoring and coaching. Both practices have been designed from organizational theories and are 'new career practices' that have emerged as alternatives to traditional techniques (Hezlett and Gibson, 2007) for the professional development of executives. As a result of the above, firms have shown a growing interest in applying mentoring and coaching in business. From the foregoing, the following hypotheses were obtained:

$\mathrm{HO}_{1}$ : $\quad$ Mentoring does not have any significant effect on organizational learning.

$\mathrm{HO}_{2}$ : $\quad$ Mentoring does not have any significant effect on adaptive capacity.

$\mathrm{HO}_{3}$ : $\quad$ Mentoring does not have any significant effect on dynamic capabilities. 


\section{Research Methodology}

This correlational study was conducted as a cross-sectional survey. The study units for data generation were employees in 31 registered and functional manufacturing companies in Port Harcourt and the micro-level of analysis was adopted. A sample size of 140 employees was determined using the Taro Yamen's formula (Baridam, 2001). After cleaning, 93 copies of the instrument were used for the analysis. In selecting the respondents the simple random sampling technique was adopted. A four-item scale was developed for mentoring. The dependent variable is Organizational resilience. The measures of Organizational resilience includes organizational learning, adaptive capacity, dynamic capabilities. Organizational learning - A five-item scale was developed based on Watkins and Marsick (2000). Adaptive capacity - A five-item scale was developed based on Folke et al., (2003). Dynamic capabilities- A five-item scale was developed based on Teece et al., 2010. A five-point Likert type scale was used (ranging from 5-strongly agree to 1- strongly disagree) for all.

For test of reliability of the scale, the following Cronbach's alpha coefficients were obtained: Mentoring (0.82), Organizational learning (0.83), Adaptive capacity (0.80), Dynamic capabilities (0.75). In accordance with Nunnaly (1978) model, which recommends a bench mark of 0.70 , the reliability levels of the study scale are acceptable. Spearman's Rank Correlation Statistical tool was used to test the hypothesis. The result as presented was obtained.

\section{Research Results And Findings}

Frequencies and descriptive were used in our primary analysis which focused on the study demographics and univariate analysis respectively. The results show that $68 \%$ of the respondents were males while $32 \%$ were females. $23.66 \%$ of the respondents are between $21-30$ years old while $34.41 \%$ are between 31 and 40 years old. $26.88 \%$ of the respondents are between $41-50$ years old. On educational qualification, we had the following distribution: $46.24 \%$ Diploma, $37.63 \% \mathrm{HND} / \mathrm{BSc}, 16.13 \%$ Masters. $26.9 \%$ of the respondents had stayed between $3-5$ years. $35.5 \%$ have stayed $6-10$ years, $37.6 \%$ had stayed above 10 years.

\section{$\mathrm{HO}_{1}$ : Mentoring does not have any significant effect on Organizational learning. Nonparametric Correlations.}

\begin{tabular}{|lll|r|r|}
\hline \multicolumn{2}{c|}{ Correlations } & \multicolumn{1}{c|}{ Mentoring } & \multicolumn{1}{c|}{ OL } \\
\hline Spearman's rho & Mentoring & Correlation Coefficient & 1.000 & $.794^{* * *}$ \\
& & & .000 \\
& Sig. (2-tailed) & 93 & 93 \\
\cline { 2 - 4 } & $\mathrm{N}$ & $.794^{* *}$ & 1.000 \\
\cline { 2 - 5 } & Correlation Coefficient & .000 &. \\
& Sig. (2-tailed) & 93 & 93 \\
\hline
\end{tabular}

* Correlation is significant at the 0.01 level (2-tailed).

The hypothesis one result in the above table indicates that there exists a statistical significant relationship between the variables. This shows that the corresponding $\mathrm{z}$ value of 0.794 at a significant value of 0.000 lies within the critical value of 0.05 confidences level, the preferred significant level. As a criterion, the null hypothesis is rejected while the alternative is accepted. Hence Mentoring has a significant effect on Organizational learning and the variables are moving in the same direction since the correlation is positive and also on the high side.

\section{$\mathrm{HO}_{2}$ : Mentoring does not have any significant effect on Adaptive capacity. Nonparametric Correlations}

\begin{tabular}{|lll|r|r|}
\hline \multicolumn{2}{c|}{ Correlations } & \multicolumn{1}{c|}{ Mentoring } & \multicolumn{1}{c|}{ Adpt. Cap } \\
\hline Spearman's rho & Mentoring & Correlation Coefficient & 1.000 & $.757^{* *}$ \\
& & Sig. (2-tailed) & .000 \\
& $\mathrm{~N}$ & 93 & 93 \\
\cline { 2 - 5 } & Adpt.Cap & Correlation Coefficient & $.757^{* * *}$ & 1.000 \\
& Sig. (2-tailed) & .000 & \\
& $\mathrm{~N}$ & 93 & 93 \\
& & &
\end{tabular}


The table above shows corresponding $\mathrm{z}$ value of 0.757 which indicates a positive and high correlation at a 0.000 significant value. This lies within the preferred level of significance of 0.05 (95\%) confidence hence the null hypothesis is rejected and the alternative accepted. Thus Mentoring has a significant effect on adaptive capacity.

\section{$\mathrm{HO}_{3}$ : Mentoring does not have any significant effect on Dynamic capability. Nonparametric Correlations}

\begin{tabular}{|lll|r|r|}
\hline & \multicolumn{1}{c|}{ Correlations } \\
\hline Spearman's rho & & Mentoring & \multicolumn{1}{c|}{ D.Cap } \\
& Mentoring & Correlation Coefficient & 1.000 & $.746^{* * *}$ \\
& & .000 \\
& Sig. (2-tailed) &. & 93 \\
& $\mathrm{~N}$ & $.746^{* * *}$ & 1.000 \\
\cline { 2 - 5 } & Correlation Coefficient & .000 & \\
& Sig. (2-tailed) & 93 & 93 \\
& $\mathrm{~N}$ & & \\
& & &
\end{tabular}

** Correlation is significant at the 0.01 level (2-tailed)

The result of hypothesis three shows a corresponding $\mathrm{z}$ value of 0.746 which indicates a high positive correlation and a significant value of 0.000 which lies within the preferred significant value of 0.05 i.e $95 \%$ confidence level. As a criterion, the null hypothesis is rejected and the alternative is accepted. Hence, Mentoring has a significant effect on dynamic capabilities.

\section{Discussion, Conclusion And Recommendation}

The three hypotheses sought to examine the effect of mentoring on the measures of organizational resilience (organizational learning, adaptive capacity and dynamic capabilities). The three hypotheses were tested using spearman rank correlation technique. From the analysis of collected data (see Tables above), a positive relationship was revealed between mentoring and measures of organizational resilience. This findings may be explained by the fact that in Nigeria, manufacturing companies are adopting mentoring programmes in their human resource management practices to ensure they have the required skills and talents that can compete favorably with the world at large and ensure that in the event of natural disaster or any other form of business catastrophe, loss of key employees etc they are sure to have a pool of talent that can keep the entire corporation going without extinction of the entity. This is in line with Gray, (1986) cited in Kelly and Lauderdale (1999) that mentoring programmes can systematically meet career development needs-thus enabling the organization to address successfully, its own need for management succession. The findings also supports Wilson and Elman,(1990) cited in Kelly and Lauderdale (1999) that mentorship provide context for socialization that transfers organizational culture, and that individual benefits for protégés are apt to translate into organizational benefits such as the stronger performance and increased loyalty.

Based on the discussions above, we conclude that Mentoring significantly affects organizational resilience (organizational learning, adaptive capacity and dynamic capabilities) within the Nigerian work environment and the manufacturing sector to be specific.

Based on the above discussions, we recommend that:

In order to ensure sustainability and growth, organizations, such as the ones at which the survey was conducted, management should focus on the factors that positively impact on their organizational resiliency. Organizations should align their HR programmes with the current demands of our time and through thorough environmental scanning install the right talents that can responsively beat their competitors. They should also develop strategies like mentoring that can prepare the business to withstand other forms of business disruptions.

\section{References}

[1]. Aggestam, L. (2006) Learning Organization or Knowledge Management- Which comes first, the chicken or the egg? Information Technology and Control Journal. Vol.35, No 3A ISSN 1392-124x. School of Humanities and Informatics, University of Skoevde. Sweden.

[2]. Agyris,C (1993) On Organizational Learning. Cambridge, MA: Blackwell.

[3]. Agulanna, C. Edward and Awujo, C. Austine (2005) Human Resource Management - A graphic Approach. Imo State. Career publishers.

[4]. Alastir M. (2010) Organizational Resilience. Understanding the concept and its application. Torrens Resilience Institute. Australia.

[5]. Amah, E (2010) Human Resource Management. Amethyst \&Colleagues Publishers, Port Harcourt

[6]. Amah, E and Baridam, D (2012) Adaptability and Organizational Effectiveness: A Study of the Tomorrow. Vol 2 No3 p122-131

[7]. Amah, E. and Daminabo-Weje, M. (2004) Fundamentals of Management. Davidstone Publishers. Port Harcourt

[8]. Amah, E and Umoh, G. I Knowledge Acquisition and Organizational Resilience in the Manufacturing Industry. Journal of Information and Knowledge Management. Vol.3 Issue 9, 2013 pp 56-63

[9]. Armitage, D. (2005) Adaptive capacity and commuocianity-basednatural resource management. Environmental Management 35,703-715. 
[10]. Bandura, A. (1977) Social Learning Theory. Englewood Cliffs NJ: Prentice Hall.

[11]. Baridam, M.D (2001) Research methods in Administrative sciences. Port Harcourt: Belk Publishers

[12]. Becker, T. W, Schulte-Pelkum, V. Blackman, D. K. Kellogg, J. B d, Richard J. O'Connell, R. J (2006) Mantle flow under the western United States from shear wave splitting. Earth and Planetary Science Letters 247 (2006) 235-251

[13]. Dalziell, E.P and McManus (2004) Resilience, Vulnerability, and Adaptive Capacity: Implications for Systems Performance. University of Canterbury. New Zealand.

[14]. Drucker, P. (2008). The Five Most Important Questions. San Francisco Jossey-Bass.

[15]. Durodie, B (2003) Is Real Resilience Attainable? The Monitor, 2(6). 15-19.

[16]. Erica Saville (2006) Resilience: What does it mean for an organization? CAE Bulletin, March.

[17]. Folke, C., Colding, J., Berkes, F (2003) Synthesis: building resilience and adaptive capacity in social-ecological systems. In: Berkes, F., Colding., Folke, C. (Eds.), Navigating Social-Ecological Systems: Building Resilience for Complexity and Change. Cambridge University Press, Cambridge, UK, 352-387.

[18]. Gunderson EK. Hourani LL (2003) The epidemiology of personality disorders in the U.S. Navy.

[19]. Military Medicine. 168(7):575-82,

[20]. Hezlett, S.A. \& Gibson, S.K. (2007) Linking Mentoring and Social Capital: Implications for

[21]. career and organisation development. Advances in Developing Human Resources 9: 384412

[22]. Kelly, M.J. and Lauderdale, M. L. "Mentoring and Organizational Learning" Social Work Executive, Winter, 1999.

[23]. Koontz, H.O.C.; and Weihrich, H. (1980). Management, 7 ed., McGraw-Hill, New York, NY, USA.

[24]. Koontz, H. O'Donnell, C and Weibrich, H (1980) Management in broader perspective, Management of Multidisciplinary study, Tokyo Macgraw Hill Publication limited.

[25]. Madni, A.M (2007) Designing for Resilience. ISTI Lecture Notes on Advanced Topics in Systems Engineering

[26]. Mallak, L., Kurstedt, Jr., H., \& Patzak, G. (1997). Planning for crises in project management. Project Management Journal, 28(4), 14-20.

[27]. McManus, S; Seville, E; Vargo, J. and Brundsdon, D. (2008). Facilitated Process for improving organization Resilience. Natural Hazards Review 9(2), 81-90.

[28]. Mitroff, I. I. (2005). From My Perspective: Lessons from 9/11 Are ompanies Better Prepared Today? Technological Forecasting \& Social Change, 72(3), 375-376.

[29]. Nunnally, J C (1978). Psychometric theory, New York

[30]. Olsson, P. (2003) Building Capacity for Resilience in Social Ecological Systems. Doctorial Dessertation, Dept of Systems Ecology, Stockholm University, Sweden.

[31]. Palmer, G. A., \& Johnson-Bailey, J. (2005) The Career Development of African Americans in the areas of Training and Organizational Development. Human Resource Planning, Vol.

[32]. 28, Issue. $1 ;$ p. 11

[33]. Parsons, D. (2007). National Organizational Resilience Framework Workshop: The Outcomes, National Organizational Resilience Framework Workshop, 5-7th December 2007, Mt. Macedon,Victoria,Australia

[34]. Pitney, W. A. and Ehlers, G. G (2004) A grounded Theory Study of Mentoring Process involved with Undergraduate Athletic Training Students. Journal of Athletic Training 39(4) 344-351

[35]. Seville, E., Brunsdon, D., Dantas, A., Le Masurier., Wilkinson, S., and Vargo, J (2008). Organizational Resilience: Researching the Reality of New Zealand Organization. Journal of Business and Continuity and Emergency Management, 2(2), 258-266.

[36]. Smith, $\quad$ D. (2002). Crisis management. Retrieved October 6, 2003, from ww.http://216.239.53.100/search?q=cache:RQzGXuasmh0C:www.shef.ac.uk/ mcn/6810/reading/crisisessay.pdf

[37]. Staber, U. and Sydow, J. (2002) Organizational Adaptive Capacity. A Structuration Perspective. Journal of Management Inquiry. Vol.11 No. 4,408-424

[38]. Sutcliff,K and Vogus,T (2003a) Organizing for Resilience. Kim, Cameron., J.E Dulton., R.E Dulton., R.E. Quinn (2003) Eds. San Francisco: Berret- Koehler.

[39]. Sutcliff,K and Vogus,T (2003) Organizing for Resilience (draft):Ann Arbor Michigan: University of Michigan, Department of Management and organizations.

[40]. Sutcliffe, K., \& Vogus, T. (2007). Organizing or resilience: Towards a theory of research and agenda. In ISIC. IEEE International Conference on Systems, Man and Cybernetics, pp. 3418-3422, 7-10 Oct.

[41]. Teece, J. D., Pisano, G., and Shuen, Amy (2010) Dynamic Capabilities and Strategic Management. Strategic management Journal. 18(7): 509-533

[42]. Tierney, K. (2003). Conceptualising and Measuring Organizational and Community Resilience: Lessons from the Emergency Response Following the September 11, 2001 Attack on the World Trade Center, Preliminary paper 329. Newark: University of Delaware.

[43]. Umoh. G.I (2009) Management Information System. With Practical case studies. Port Harcourt: Blue Print Limited

[44]. Umoh, G. I and Amah, E. (2013) Knowledge Acquisition and Organizational Resilience in the Nigerian Manufacturing Organizations. Journal of $\quad$ Information Management. Vol.3 Issue 9, pp 56-63

[45]. United Nations (2005) Report of the world conference on Disaster Reduction. Kobe, Hyogo, Japan, $18^{\text {th }}-22^{\text {nd }}$ January. Vanguard Newspaper, November $13^{\text {th }}, 2011$. Nigeria.

[46]. Wackins, K. and Marsiek, V. (2000) Dimensins of Learning the Organization Quetionnaire.www.organizational learning .com

[47]. Walker, W.J (1980) Human Resource Planning U.S.A: McGraw-Hilland.

[48]. Walker, B.H., Carpenter, S.R., Anderies, J.M., Abel, N., Cumming, G.S., Janssen, M.A., Lebel, L., Norberg, J., Peterson, G.D., Pritchard, L., (2002) Resilience management in social-ecological systems: a working hypothesis for a participatory approach. Conservation Ecology 6: 14. Online: http://www.consecol.org/vol6/iss1/art14/. Downloaded 16.07.07.

[49]. Weick, K. E., \& Sutcliffe, K. M. (2007). Managing the Unexpected. San Francisco: Jossey-Bass.

[50]. William, M. L; Malos, S.B.; Palmer, D.K. (2002). Benefit system and benefit level satisfaction: An expanded model of antecedents and consequences. Journal of Management, 28(2):195-215. 